\title{
WPAN Based Cattle Health Monitoring With Labview as A Data Logger
}

\author{
Ateev Agarwal ${ }^{1}$, Eesh Mehandiratta ${ }^{2}$, Rohit Sanket $^{3}$, Rohit Samkaria ${ }^{4}$, Ambujaksh \\ Shah $^{5}$, Rajesh Singh ${ }^{6}$ and Anita Gehlot ${ }^{7}$ \\ ${ }^{1-7}$ College of Engineering Studies, University of Petroleum and Energy Studies, \\ Dehradun, India \\ Iateevag@gmail.com,2eeshmehandiratta297@gmail.com \\ ,3rohitsanket@gmail.com , ${ }^{4}$ rohit.samkaria93@gmail.com, ${ }^{5}$ \\ shah.ambuj08@gmail.com, ${ }^{6}$ rsingh@ddn.upes.ac.in, ${ }^{7}$ anita@ddn.upes.ac.in
}

\begin{abstract}
A wireless cattle health monitoring system to measure health and psychological parameter of cattle has been developed using environmental temperature and humidity, body temperature, rumination, heartbeat, and sweat sensors. The system developed is capable to analyze stress level of cattle's with reference to THI (Thermal Humidity Index). System is developed according to IEEE1451.1, 1451.2, and 802.15.4 standards. The ATmegal6 controller and zigbee has been used to develop the wireless sensor and receiver nodes. LabVIEW is used as a real time data logger for monitoring the output of various sensors over the $P C$. This real time data monitoring is much inexpensive technique for monitoring of health of livestock. Power consumption of the device has been kept minimum. The device is successfully designed, made, and tested.
\end{abstract}

Keywords: WSN, Atmegal6,Xbee, , LabVIEW

\section{Introduction}

In recent times, due to increase in pollution and global warming environmental parameters like temperature, humidity etc. are changing very rapidly. This has caused livestock farmers to face many cattle health related problem due to continuous rise in environmental temperature like swine fever, squamous cell carcinoma ,bovine rhinotracheitis ,necrotic pododermatitis, web tear, warts, hypomagnesaemia, clostridia disease and polioencephalomalacia[1-2]. It has also been stated in WHO report that SARS-CoV is animal virus that spreads to other animals and have also effected the human directly and the first case was reported in China in 2002 and after that till 2003, 26 countries reported the infection caused by SARS [3]. So due to this reason it is needed to monitor these various parameter and avoid them to spread globally [3]. In agriculture, the diary sector is one of the biggest production in the world and for successful rise in this production various researchers are nowadays focusing on the development of the animal health monitoring system.

The two methods which are mostly utilized for the health monitoring are invasive and non-invasive and a prototype of telemonitoring consists of the sensing unit which is placed within the cattle and the receiving unit which is placed at remote location is attached with the computer. Smith et al proposed a cattle health monitoring system and they mainly focused on the body temperature, head motion and heart rate [8]. The various parameters of cattle are monitored by sensor module which is placed on the belt placed at the neck of the cattle. The core of the system is atmega16 controller which is placed over the board that continuously monitoring the data of these sensors and transmitting this data through wireless RF Modem to the surrounding. Each controller board have UNID 
number which differentiate each cattle and in this way multiple board with their UNID transmits the data. In the receiving section the incoming data is differentiated by their UNID. The RF Modem at receiving side collects the data and this data is mapped with the Graphical User Interface through LabVIEW. The LabVIEW provides all parameters for each UNID which are monitored with ease. L. Nagl et al proposed a system that consists of a suite of sensor that communicate wirelessly with the base station via Bluetooth telemetry [5]. L. A. Gonza'lez et al developed an algorithm to monitor short term feeding behavior of dairy cow as feeding can tell us a lot about the health of any animal. The algorithm resulted is detection of acute disorders in cows at least $1 \mathrm{~d}$ before diagnosis by the farm staff in more than $80 \%$ of the cows [4]. Rifat Shahriyar et al. (2009) introduced an intelligent mobile health Monitoring System (IMHMS) to monitor the health of cattle, the system could provide patients medical feedback through mobile device [6]. Chakchai So-In et al. (2012) developed a prototype with an ATmega16 microcontroller with various sensors, GPS and GSM and used bar signs for mobile monitoring and searching animals [7]. Riaz Ahamed (2005) presented the role of Zigbee based wireless Technology in future data communication for animal tracking [10]. With all this advancement in technology still there is no product in the market to successfully measure cattle health and livestock farmers face a lot of problem to monitor the health of livestock. Reports have revealed that wearable animal health monitoring technology helps veterinary staff a lot as measuring parameters can provide a lot of animal health related information.

In this paper, we have proposed a reliable, economic, energy efficient and tested livestock health monitoring system which can measure body temperature, sweating, rumination, heart rate with surrounding temperature and humidity to successfully measure the psychological and external body parameters of livestock. Sweating and rumination of animal is a very important parameter which could tell us all about external and mental condition of any animal that weather animal is in any stress or not.

\section{Proposed System}

Figure below show the general architect of proposed system that is based on ATmega16 microcontroller which measures cattle's body temperature, sweating, heartbeat, and rumination with surrounding temperature and humidity to successfully measure psychological and external parameters of dairy animals. All the sensed parameter is then transmitted via zigbee to the receiver module which is attached to the developed GUI on LabVIEW which continuously monitors the health of the cattle and notifies the farmer if any parameter moves beyond the defined value.

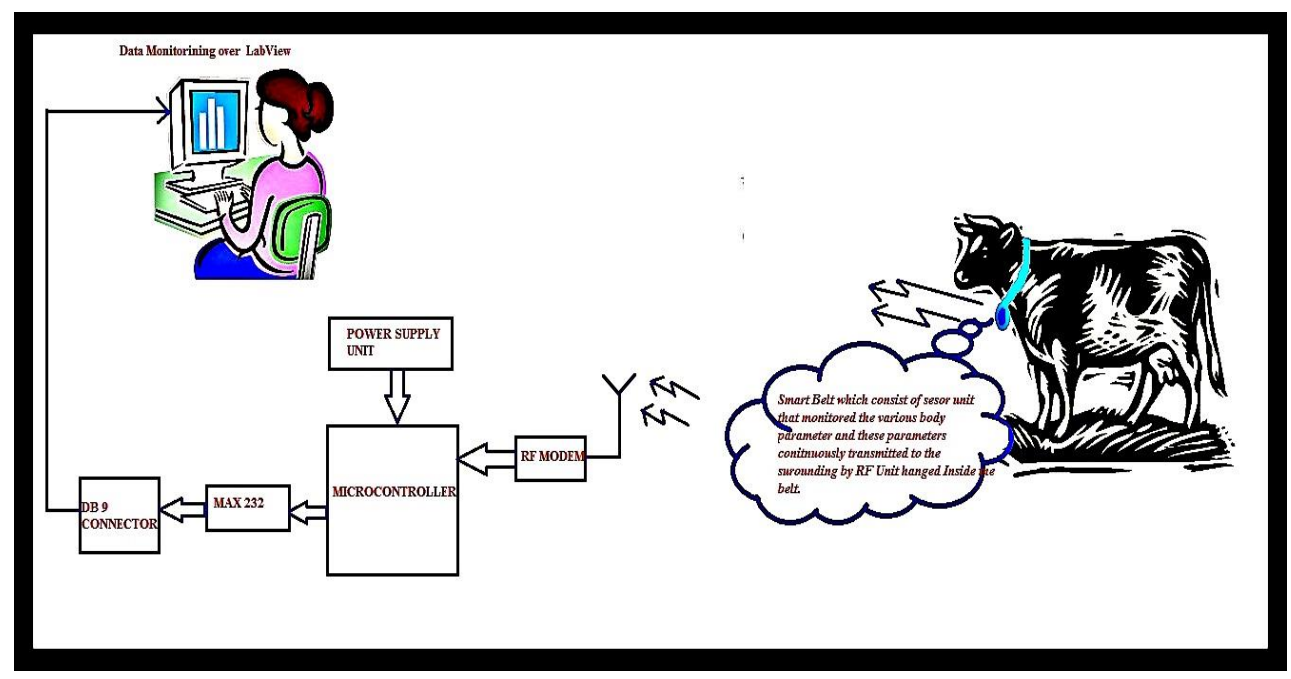

Figure 1. General Diagram of System 


\section{Sensing Module}

This is most important module of our proposed system. It consists of sensor, microcontroller and zigbee module. The proposed device is equipped with six sensors namely body temperature sensor, sweat sensor, rumination, heartbeat, environmental humidity and temperature sensors. The sensor unit is fitted on a collar belt which could fit on any dairy animal. The sensor data is fed to the microcontroller which then send the data to receiver via zigbee. The detail of the sensors used is given below.

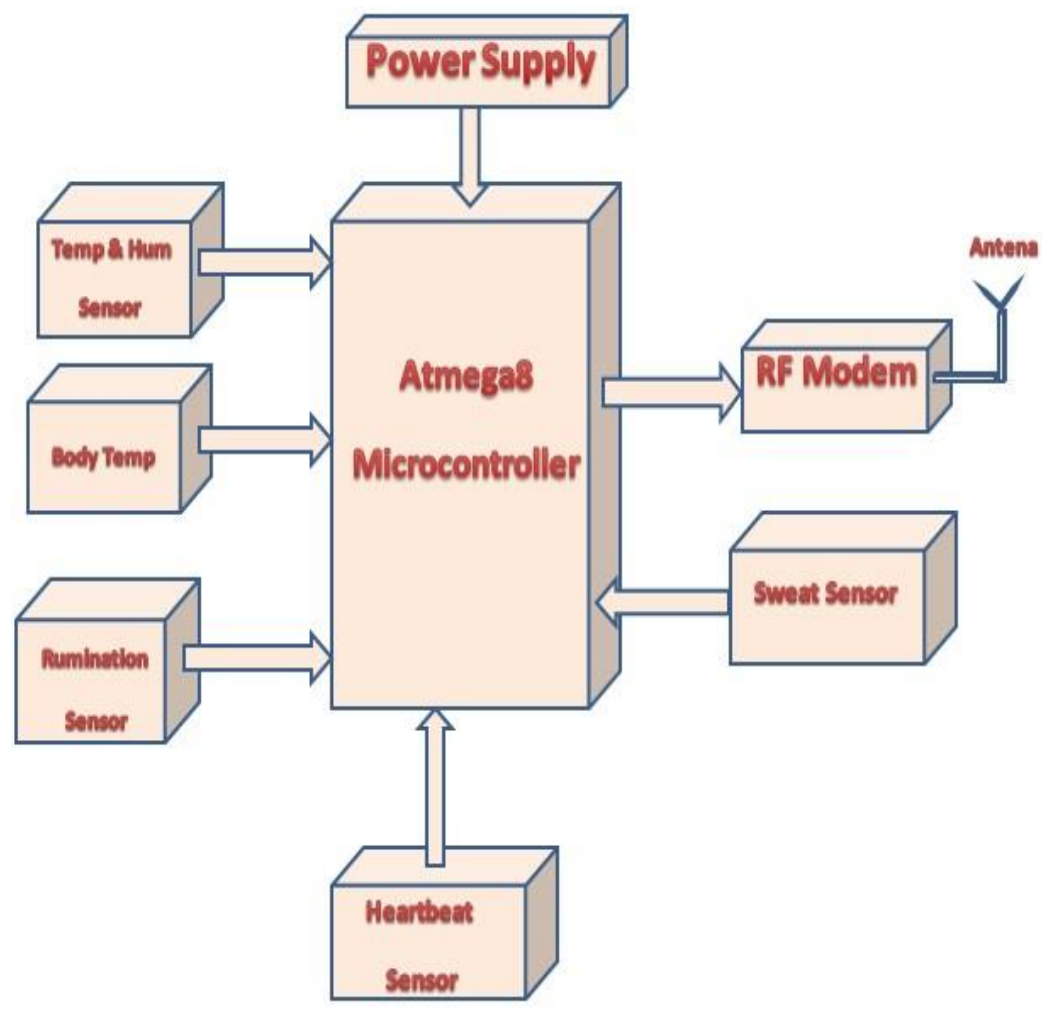

Figure 2. Block Diagram of Cattle Health Monitoring System

\subsection{Body Temperature Sensor}

Cattle's have CBT (core body temperature) in which there metabolism works without modification, termed as thermo neutral zone. CBT is generally greater than the surrounding temperature to dissipate the heat produced during the metabolism. Even relatively narrow deviation outside this range can increase in resting metabolism, cellular physiology modifications and biochemistry as well as the animal's behavior (Shearer and Beede, 1990). The thermo neutral zone of the dairy cattle lies between 41 and $77{ }^{\circ} \mathrm{F}$ (5 and $25^{\circ} \mathrm{C}$ ) (Roenfeldt, 1998). Above $77^{\circ} \mathrm{F}$, physiology and behavior must be modified to keep CBT more than ambient temperature. Elevated CBT caused by heat stress in dairy cows could effects their reproductive performance also. A healthy cow has a normal body temperature of approximately between $38.6^{\circ} \mathrm{C}\left(101.5^{\circ} \mathrm{F}\right)$ to $39.6^{\circ} \mathrm{C}\left(103^{\circ} \mathrm{F}\right)$ [11]. According to weather reports average temperature in India varies from $35^{\circ} \mathrm{C}$ with the lowest mean temperature being $15^{\circ} \mathrm{C}$. Therefore the good range for our ambient temperature monitoring is $-5^{\circ} \mathrm{C}$ to $+45^{\circ} \mathrm{C}$. Thermistor (TTC05102) with negative temperature coefficient (NTC) has been selected for the temperature measurement because it is highly sensitive resistor which changes its resistance with temperature. The resistance of NTC thermistor decreases with increase in temperature. Its response with 
respect to temperature is very fast and accurate and have a less complicated circuitry, light weight and economic. Figure-3 shows the thermistor schematic diagram.

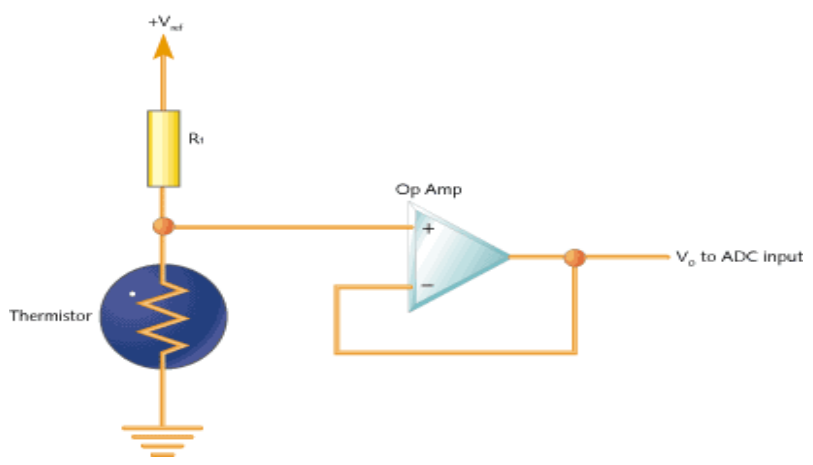

Figure 3. Schematic Diagram of Temperature Sensor Module

\subsection{Humidity Sensor}

Many environmental factors affects the health of cattle and their productivity. The factors could be heat, humidity, radiation etc. we are going to study environmental temperature and humidity, the two factor which affect the health most. We are going to determine THI which measures combined effect of relative humidity and temperature [12]. We are going to use DTH11 humidity and temperature sensor.

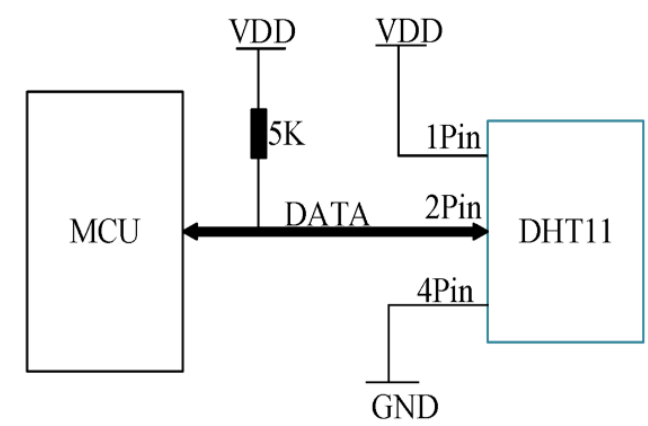

MCU: Microcontroller unit

DHT11: Temperature and humidity sensor

Figure 4. Temperature and Humidity Sensor Schematic

\subsection{Sweat Sensor}

We have used GSR (Galvanic skin response) method to measure sweating in animals. In this method we are going to measure the electrical conductance of the skin, which is varying with the level of skin moisture. The sweat glands which are controlled through sympathetic nervous system in the living being shows the emotions or stress causing change in the electrical resistance of the skin. Physiological or psychological arousal in any animal could be indicated by change in skin conductance [12-13]. The device which we have used measures electrical conductance between two points on the body, and is essentially a type of ohmmeter. 


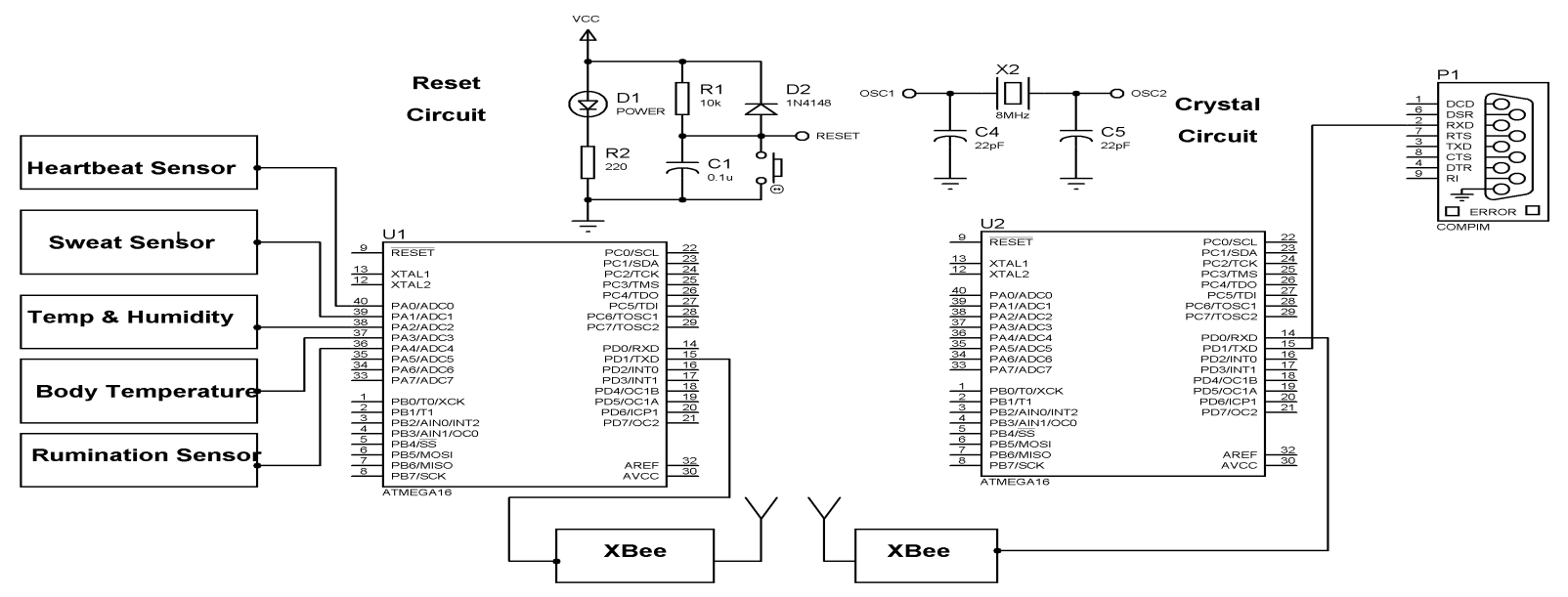

Figure 5. Circuit Diagram of the Model

\subsection{Heartbeat Sensor}

Heart pulse is one of the most important parameter in determining the health of the cattle. Any variation in the pulse rate is an indicator of stress, movement, exertion and disease. The average pulse rate of an adult healthy cow is 48 to 86 beats per minute [18, 20]. Heart pulse measurement is an indirect method of the measurement of health.

Many researchers have used polar sport tester (PST) for the measurement of pulse rate. We are going to use polar equine $\mathrm{T} 56 \mathrm{H}$ for the measurement of pulse rate of cattle. The polar equine transmitter $\mathrm{T} 56 \mathrm{H}$ consists of two electrode pads on each side of the transmitter. The electrode with the Velcro is the positive electrode and the other one is negative. The polar equine transmitter is shown in figure-6.

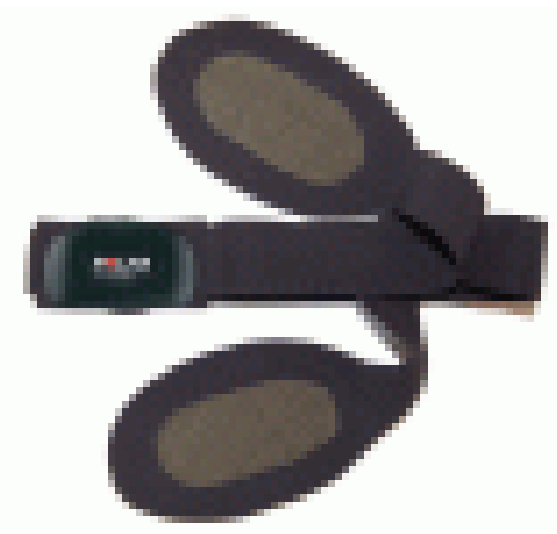

Figure 6. Polar Equine Transmitter

\subsection{Rumination sensor}

Rumination is one of the important factor that indicates the wellbeing on an animal. Most of the animals ruminate for 9-10 hour a day. Any change in rumination indicates indigestion, mastitis, metabolic calving disease etc. Rumination is the function of how well animal is resting and what they eat. Veterinarians require rumination monitor because rumination data can provide them accurate data of animal's wellbeing [20-21]. We are going to use an ADXL335 Triple-Axis Accelerometer Module to measure rumination of the cattle which could be fitted on the mouth of the cattle [22]. The sensor modules schematic is shown in figure 7. 


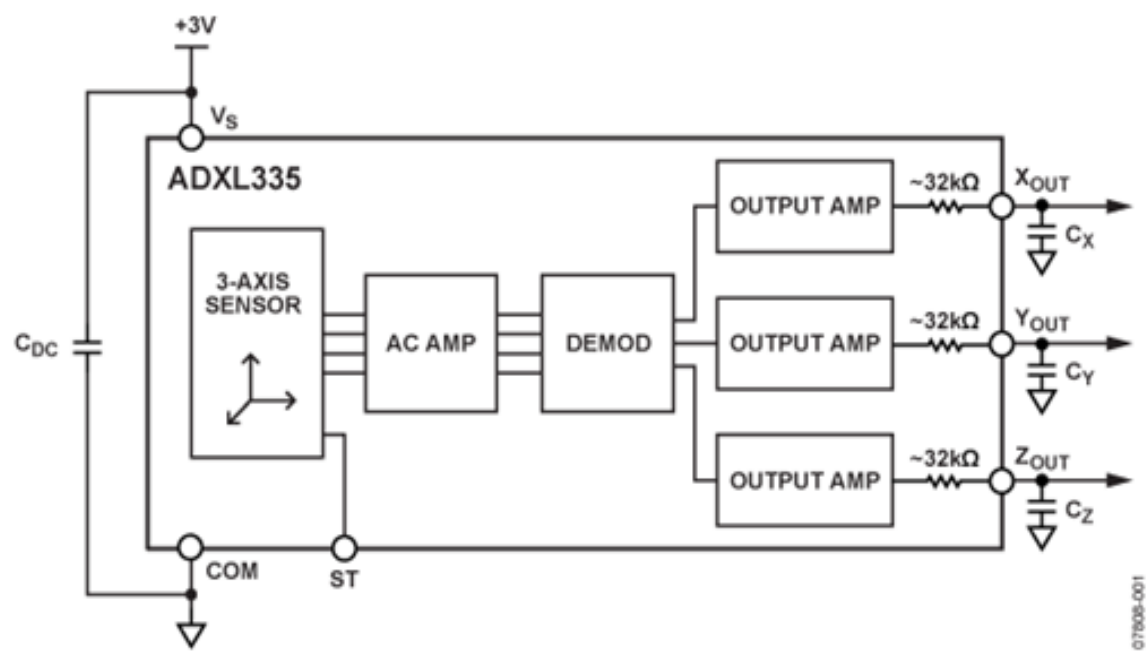

Figure 7. Accelerometer Schematic

\section{Wireless Communication}

In the development of our prototype of cattle health monitoring system we have used Zigbee communication. We have used Zigbee because as it is energy efficient, good data transfer rate, it has a unique id which differentiate each module from another and low cost communication module [27], [30]. Zigbee communication has multiple applications such as smart farm, environment monitoring, forest fire monitoring, telemedicine service, XBee WSN for Heartbeat Monitoring and other industrial applications [28-29]. We have used XBee pro in our prototype. The advantages, specifications and disadvantages of zigbee communication and XBee is given in [25], [30]. XBee works on unlicensed 2.4 $\mathrm{GHz}$ frequency band and the data is transferred and received serially through UART (universal asynchronous receiver transmitter). We have used putty software to configure our XBee. Each node (sensor as well as sink) is given a unique ID so that each cattle could be identified and same PAN (personal area network) id so as to form a mesh network i.e. each sensor node can send data to any sensor node therefore even if the cattle is not in range of the sink module, data can be reached to sink. In our prototype, we have developed two sensor node whose data converges to a single sink node.

\section{Receiver Module}

The receiver collects the data from all the sensor modules. The sensor module consists of zigbee connected with a microcontroller which receives the data serially from all the sensors using UART. The microcontroller is connected to a PC which consists of a labVIEW panel that is used to display all the sensor reading and notifies the caretaker if any parameter exceeds the specified value.

\subsection{GUI (Graphical User Interface)}

We have used labVIEW software to develop our GUI which is installed in PC. The PC is connected with microcontroller via USB, we have used USB to connect microcontroller and PC because it is easy to interface them via USB, high data accuracy, cost efficient etc. Microcontroller receives data from all sensor nodes and transfer it to PC which can be seen on the Graphical user interface. The GUI has two main programs that is front panel and block diagram [32], [33]. We have used VSP (virtual serial port) emulator to 
communicate between the computer port and LabVIEW virtual port.. Figure 8 shows developed GUI front panel.

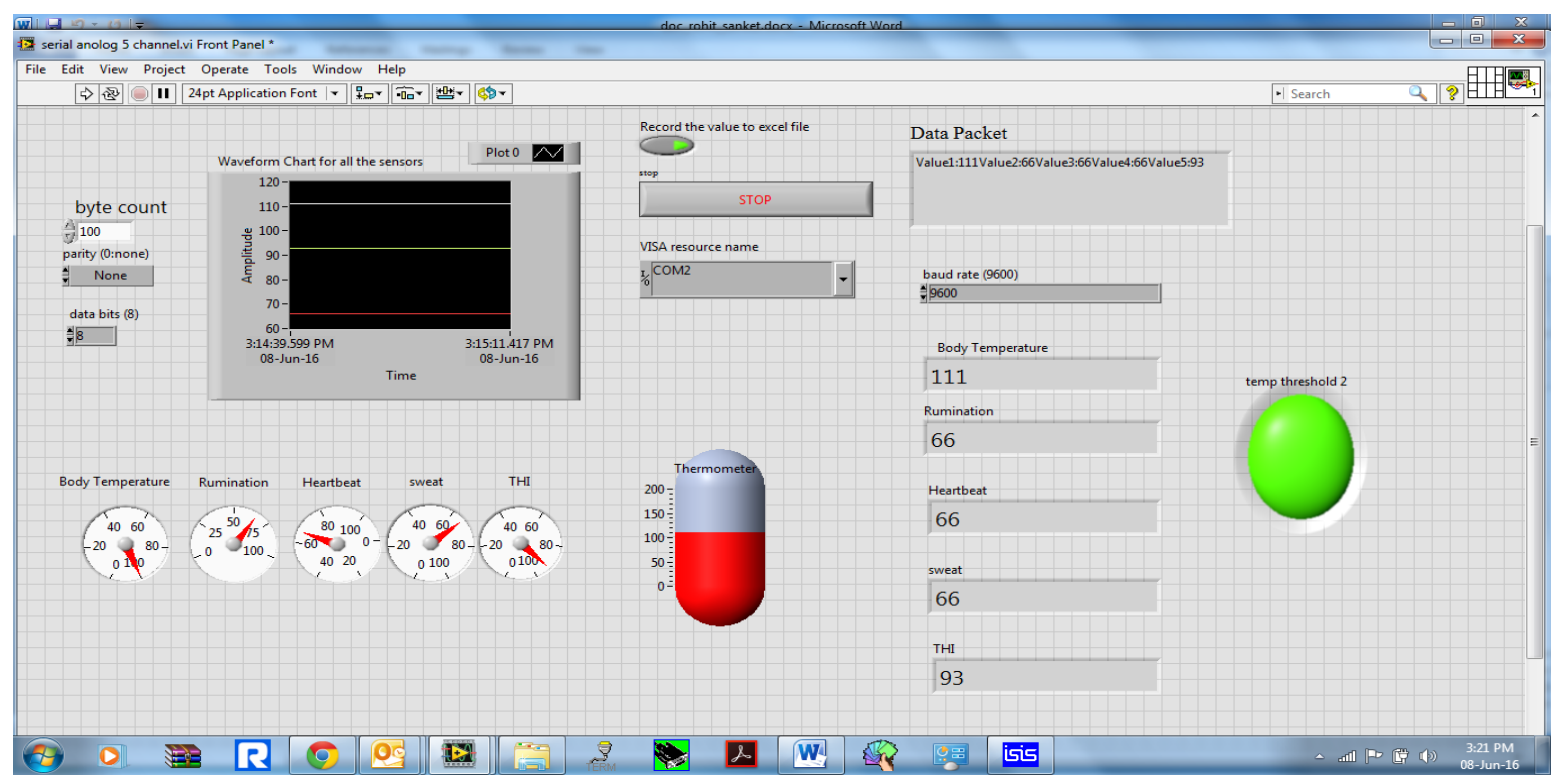

Figure 8. LabVIEW Front Panel

\section{Stress Indicator}

Environmental temperature and humidity has an adverse effect on cattle's milk production rate, weight gain, reproduction efficiency etc. that is why proper environment must be maintained for the cattle's for their efficient production and reproduction.

The stress of the cattle can be determined through THI (thermal humidity index). The THI is the real time monitoring of environmental temperature and relative humidity. To calculate THI, the equation- 1 has been used.

$\mathrm{THI}=(18 / 10 * \mathrm{~T}+32)-[(55 / 100-0.0055 * \mathrm{RH}) *(18 / 10 * \mathrm{~T}-268 / 10)]$

Where $\mathrm{T}$ is surrounding temperature in degree Celsius and RH is relative humidity. As the relative humidity is increased at any temperature, it becomes more difficult for the animals to cool themselves. The table-I shows the THI v/s stress level of the cattle during experiment [37].

Table 1. THI v/s Stress Level

\begin{tabular}{ll|l} 
Stress Level & Comment & THI \\
\hline none & & $<70$ \\
\hline Mild & Respiration increases. & $70-79$ \\
\hline Moderate & $\begin{array}{l}\text { Increased respiration, saliva, } \\
\text { and temperature. }\end{array}$ & $80-89$ \\
\hline Severe & $\begin{array}{l}\text { Increased respiration and } \\
\text { temperature and excess } \\
\text { saliva }\end{array}$ & $90-98$ \\
\hline Danger & Animal death can occur & $>98$ \\
\hline
\end{tabular}

\section{Result and Discussion}

The research paper is on the development of a cattle health monitoring system which will measure surrounding temperature and humidity, cattle's temperature, rumination, sweat and heartbeat. The base of the system is on the IEEE 1451.1, 1451.2, and 802.15.4 standards. The prototype which consists the temperature, humidity, sweat \& rumination 
sensor is successfully developed using an ATmega 16 microcontroller and tested. The parameter which we are measuring is helpful to measure the health of the animal. The developed module can transmit data upto 20 meters which could be extended upto 50-100 $\mathrm{m}$ if we use mesh network topology.

We have also developed a LabVIEW based front panel which can handle measuring parameter functions such as ON/OFF, saving the data in the database of computer, setting time interval of the

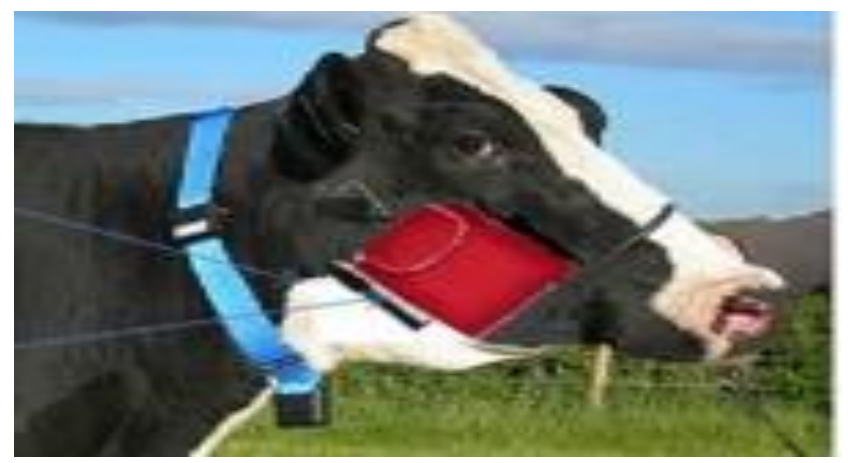

Figure 9. Real Time Implementation

output of sensor, graphical and digital output. The developed GUI is capable to display 5 sensor parameter and psychological parameter of the cattle. The major cost of power consumption of the developed device is only due to the sensor node as the sink module is attached to the PC containing the GUI. The PC's USB port is capable to supply 100mA of current at $5 \mathrm{~V}$ which is sufficient for our receiver module. We have attached $9 \mathrm{~V}$ battery to our sensor module which can send data continuously for 60-65 hours before recharging again. The device has been developed keeping in mind the comfort of the animal. To protect the device from other environmental phenomenon PVC (polyvinyl chloride) coating has been applied on the device. The prototype setup with the cattle is shown below in figure 9 .

\section{Conclusion}

The developed prototype consists of a number of sensor modules and a receiver module which is attached to PC that contains GUI. The prototype has been designed according to IEEE standards. Low power consumption of the device has been kept in mind while developing the prototype for which we have used electronic components which use minimum power. The device can run continuously maximum time. We have also kept in mind cost efficiency of the device, most of the components used are cheap. Major cost of the device is coming from ATmega-16 controller and zigbee modules.

For future study, we can make this device more flexible so as to increase the comfort of the cattle wearing the device. Furthermore we can add new sensors and increase the range of the device which can be done by implementing ultra wide band (UWB) radio based WSN. Or we can change few existing sensors to make the device more effective and efficient.

\section{References}

[1] T. T Preston and M. B. Willis, "Intensive beef production", (1970), p. 287.

[2] K. A. Whitman, "Finfish and shellfish bacteriology manual: techniques and procedures", Iowa state press, (2004).

[3] W. A. Infl and U. Manu, "WHO manual on animal influenza diagnosis and surveillance", Geneva: World Health Organization, (2002).

[4] L. A. González, "Changes in feeding behavior as possible indicators for the automatic monitoring of health disorders in dairy cows", Journal of Dairy Science, vol. 91, no. 3, (2008), pp. 1017-1028. 
[5] L. Nagl, "Wearable sensor system for wireless state-of-health determination in cattle", Proceeding of the 25th Annual International Conference of the IEEE EMBS, Cancun, Mexico, (2003).

[6] R. Shahriyar, "Intelligent mobile health monitoring system (IMHMS)", Electronic Healthcare, Springer Berlin Heidelberg, (2009), pp. 5-12.

[7] C. S. In, "Mobile Animal Tracking Systems using light sensor for efficient power and cost saving motion detection", Communication Systems, Networks \& Digital Signal Processing (CSNDSP), 2012 8th International Symposium on IEEE, (2012).

[8] A. Kumar and G. P. Hancke, "A Zigbee-based animal health monitoring system", Sensors Journal, IEEE, vol. 15, no. 1, (2015), pp. 610-617.

[9] C. C. G. Yaashuwanth and P. Prabhavathy, "Health monitoring and management system for dairy animals", Indian Journal of Animal Research vol. 48. no.6, (2014).

[10] S. S. R. Ahamed, "The role of zigbee technology in future data communication system", Journal of Theoretical and Applied Information Technology, vol. 5, no. 2, (2009), pp. 129.

[11] Allen, J. D., et al. "Managing heat stress and its impact on cow behavior."28 th Annual Southwest Nutrition and Management Conference. 2013.

[12] Bohmanova, J., I. Misztal, and J. B. Cole. "Temperature-humidity indices as indicators of milk production losses due to heat stress." Journal of Dairy Science 90.4 (2007) 1947-1956.

[13] Lawrence, Emerson Smith. "Temperature-humidity index measuring device." U.S. Patent No. 3,254,532. 7 Jun. (1996).

[14] Dashboard, My, and Top Picks. "Galvanic skin response."

[15] Bitterman, M. E., and Wayne H. Holtzman. "Conditioning and extinction of the galvanic skin response as a function of anxiety." The Journal of Abnormal and Social Psychology 47.3 (1952) 615.

[16] Shi, Yu, et al. "Galvanic skin response (GSR) as an index of cognitive load."CHI'07 extended abstracts on Human factors in computing systems. ACM, 2007.

[17] McCleary, Robert A. "The nature of the galvanic skin response."Psychological Bulletin 47.2 (1950): 97.

[18] Hopster, Hans, and Harry J. Blokhuis. "Validation of a heart-rate monitor for measuring a stress response in dairy cows." Canadian Journal of Animal Science 74.3 (1994): 465-474.

[19] Janzekovic, M., et al. "The art equipment for measuring the horse's heart rate." ISSUES 1 (2010): 2.

[20] Brosh, A., Y. Aharoni, and Z. Holzer. "Energy expenditure estimation from heart rate: validation by long-term energy balance measurement in cows."Livestock production science 77.2 (2002): 287-299.

[21] Metz, Jozephus Hermanus Maria. Time patterns of feeding and rumination in domestic cattle. Vol. 5. Veenman, 1975

[22] Kennedy, P. M. "Effect of rumination on reduction of particle size of rumen digesta by cattle." Crop and Pasture Science 36.6 (1985): 819-828.

[23] Martiskainen, Paula, et al. "Cow behaviour pattern recognition using a three-dimensional accelerometer and support vector machines." Applied Animal Behaviour Science 119.1 (2009): 32-38.

[24] Chambers, A. R. M., J. Hodgson, and J. A. Milne. "The development and use of equipment for the automatic recording of ingestive behaviour in sheep and cattle." Grass and Forage Science 36.2 (1981): 97-105.

[25] Alliance, ZigBee. "Zigbee specification." (2006).

[26] P. Baronti, "Wireless sensor networks: A survey on the state of the art and the 802.15. 4 and ZigBee standards", Computer communications, vol. 30, no. 7, (2007), pp. 1655-1695.

[27] J. S. Lee, Y. W. Su, and C. C. Shen, "A comparative study of wireless protocols: Bluetooth, UWB, ZigBee, and Wi-Fi." Industrial Electronics Society, 2007. IECON 2007. 33rd Annual Conference of the IEEE. IEEE, (2007).

[28] N. S. A. Zulkifli, F. K. C. Harun and N. S. Azahar, "XBee wireless sensor networks for Heart Rate Monitoring in sport training", Biomedical Engineering (ICoBE), 2012 International Conference on. IEEE, (2012).

[29] V. Boonsawat, "XBee wireless sensor networks for temperature monitoring", the second conference on application research and development (ECTI-CARD 2010), Chon Buri, Thailand, (2010).

[30] W. A. N. G. Jingxia, “Application of zigbee/ieee 802.15. 4 protocol compatible rf module xbee/xbee pro [j]”, Electronic Engineer, vol. 3, (2007), p. 008.

[31] R. Faludi, "Building wireless sensor networks: with ZigBee, XBee, arduino, and processing, O'Reilly Media, Inc.", (2010).

[32] K. L. Wells and J. Travis, "LabVIEW for everyone: graphical programming made even easier", Prentice-Hall, Inc., (1996).

[33] Travis, Jeffrey, and Jim Kring. LabVIEW for Everyone: Graphical Programming Made Easy and Fun (National Instruments Virtual Instrumentation Series). Prentice Hall PTR, (2006).

[34] Beyon, Jeffery Y. LabVIEW programming, data acquisition and analysis. Prentice Hall PTR, (2000).

[35] Warren, Steve, Jianchu Yao, and G. Edward Barnes. "Wearable sensors and component-based design for home health care." Engineering in Medicine and Biology, 2002. 24th Annual Conference and the Annual Fall Meeting of the Biomedical Engineering Society EMBS/BMES Conference, 2002. Proceedings of the Second Joint, vol. 3, (2002). 
International Journal of Future Generation Communication and Networking

Vol. 9, No. 6 (2016)

[36] C. Elliott, Chance, "National instruments LabVIEW: a programming environment for laboratory automation and measurement", Journal of the Association for Laboratory Automation, vol. 12, no. 1, (2007), pp. 17-24.

[37] L. E. Chase, "Climate change impacts on dairy cattle," NY: Ithaca, (2013). 